\title{
THE STRUCTURE OF PATENT AUTHORSHIP NETWORKS IN JAPANESE MANUFACTURING COMPANIES
}

\author{
Kohei Tsuda, Frank J. Rinaldo, Victor V. Kryssanov, Ruck Thawonmas \\ Faculty of Information Science and Engineering, Ritsumeikan University, Kusatsu, Shiga, Japan \\ tsuda@ice.ci.ritsumei.ac.jp, rinaldo@is.ritsumei.ac.jp,kvvictor@is.ritsumei.ac.jp,ruck@ci.ritsumei.ac.jp
}

Keywords: Patent, Inventorship networks, Power law.

Abstract: Technological and research strategies are becoming more significant as they create future value in the market. The core of these strategies is the creation of patents, which help eliminate or contain competition. Companies seek to learn the research strategies of their competitors. At the same time, all companies try to hide their own strategies but they generally cannot, because patents have to be filed and therefore exposed at a patent office and even made globally (e.g. via the WWW) accessible on-line. Part of the technological strategy of a company can be determined by observing the patents it files, their timing and their authors. There have been many studies about patents reported in the literature, with most of them focusing on the connectivities existing in co-citation, co-patent networks. In the presented work, the focus is on the inventors. Given the patent files of a company, one could possibly predict the company's current and future research and production strategies. Furthermore, if the inventors are known, the human resources of the corresponding companies could naturally be scrutinized. The latter would allow to estimate the mechanism prevailing in the process of patent creation at a specific company. A novel approach to analyze the professional activities of company inventors is proposed and applied to determine the inventive strategy of Japanese manufacturing companies. The presented results can be used to optimize knowledge and recourse management within a company.

\section{INTRODUCTION}

Technological strategies are becoming more significant as they create future value in the market (Probert and Shehabuddeen, 1999; Burgelman et al., 2003). The core of these strategies is the creation of patents that helps eliminate or contain competition. Companies also need to learn the patent strategies of their competitors (Rivette and Kline, 2000).

At the same time, all companies need to hide their own technological strategies but cannot, because patents have to be published at a patent office as quickly as possible. As a result, part of the technological strategy of a company can be determined by observing the patents it files, their timing and their authors.

There have been many studies reported in the literature about patent/authorship networks. Most of them deal with the structure of the authorship and focus on the patent system and its surroundings. There are studies that explore the grouping of patents through a bibliographic coupling analysis (Huang et al., 2003) and the linking of science and technology as revealed with bibliographic references (Verbeek et al., 2002). A recent study suggests that there are two mechanisms of patent diffusion: geographic localization of knowledge flows and concentration of knowledge flows within company boundaries (Singh, 2005). Many works described knowledge diffusion and flow by using complex network theory (Chen and Hicks, 2004); target areas included industries (Meyer, 2001), universities (Jaffe and Trajtenberg, 1996), and global enterprises (Tijssen, 2001).

Much of the current research is therefore about patent citations, yet as a rule it targets multinational corporations (Verspagen, 2000; Bhattacharya and Meyer, 2003). Researchers tend to focus on the structure of patent co-citation and generally on patent networks (Mogee and Kolar, 1999). These studies analyze knowledge diffusion through patent citation, but there are few studies that attempt to utilize these analyses to improve the efficiency of patent creation process. There is little information available on the management mechanism to create patents effectively and on inventor networks. 
The purpose of this work is to explore the mechanisms responsible for the creation of patents at different manufacturing companies. A model of these mechanisms is proposed and used to analyze the professional activities of company inventors using patent authorship data.

Figure 1 provides a conceptual view used in the presented study. The patent data is taken from the Japanese Patent Authorship Network; it includes 7,396 inventors filing 9,349 patent applications. In Section 2, characteristics of the patents, the inventors, and their social network are discussed. In Section 3, a sketch of the system-theoretic analytic framework used in this study is given, and Section 4 presents a case study. Finally, Section 5 discusses characteristics of the patent creation process and Section 6 gives concluding remarks and outlines directions for future research.

\section{PATENTS AND INVENTORS}

Patents are created by inventors, and their authorship is similar to that of academic papers. One might assume that the academic authorship analysis might be used to investigate the process of patent creation (Liu et al., 2005).

The above analogy does not however work. Patents as a rule have a strategic (and financial) significance, while academic papers do not, and the academic citation studies are not readily applicable for inventor network.

Inventors are usually researchers at companies with $R \& D$ sections. While there are many individual inventors in the US, in Japan almost all inventors (and their patents) are affiliated with companies.

What is an inventorship network? It is the list of researchers and their inventions, and their corroborative efforts. It reflects the professional relationships that exist between the authors in the process of working on a patent. Invention activities assume communication and exchange of ideas, and if there are co-authors (co-inventors), there is usually a strong connection between them as indicated by the patent (authorship) network. If such collaborating individuals are co-authors on more than one patent, the corresponding professional connection is even stronger.

Who would be considered as the most important person in a company's R\&D? Probably the person who has the greatest number of patents; this may however not necessarily be so. In Japan, it has been the case for a researcher's superiors to be included as a patent author. This could distort who might be

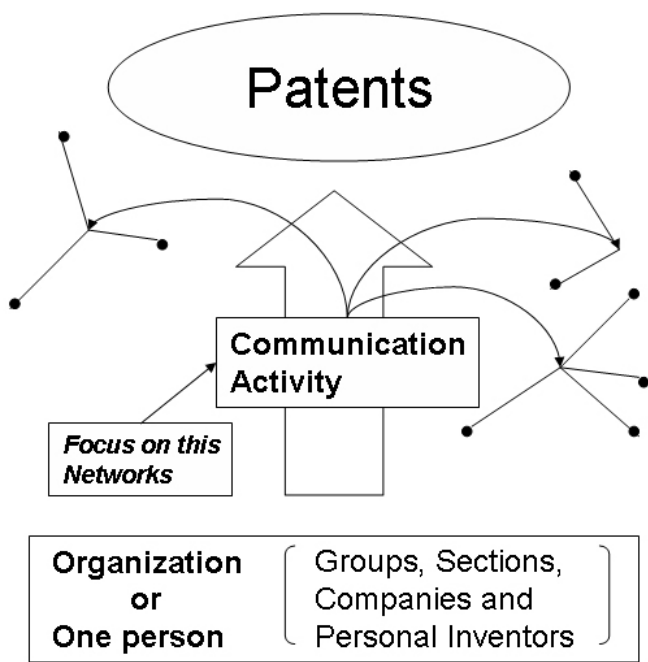

Figure 1: The concept of the study: focusing on communication networks of inventors.

the most important person as a high level manager could have his name on many patents with very little contribution. People having a number of registered patents are probably important, but the truly essential person is the one who is the most "truly" influential to other researchers.

\section{THE ANALYTIC APPROACH}

A complete (whatever it would mean in the given context) theory of social interactions requires a theoretical understanding of statistical regularities observed in or simply associated with the social system under examination. The most often cited (and overwhelmingly best studied) approach to the study of various networks having a social origin is Zipf's "principle of least effort" (cumulative advantage, preferential attachment, etc), yet sometimes presented as simply the power law. The latter law states that the frequency of a link (contact, citation, authorship, etc.) decays as a power function of its rank (Newman, 2005). It should be noted however, that despite the apparent relevance and proven universality of this law, it can be obtained from a variety of mechanisms (Mitzenmacher, 2003) and by itself, it does not provide insights about the organization of the social system, the system's dynamics and evolution.

In an attempt to establish a theoretical basis for the investigation of inventorship networks, the presented study exploits the analytic framework 
Table 1: IPC categories used for sampling.

\begin{tabular}{|l|l|l|lll|}
\hline Section & Class & Subclass & Description & \\
\hline \multirow{2}{*}{$\mathrm{B}$} & 81 & All & $\begin{array}{l}\text { MICRO-STRUCTURAL } \\
\text { SYSTEMS }\end{array}$ & DEVICES & OR \\
\cline { 2 - 5 } & 82 & & NANO-TECHNOLOGY & \\
\hline $\mathrm{H}$ & 02 & $\mathrm{~N}$ & $\begin{array}{l}\text { ELECTRIC MACHINES NOT } \\
\text { PROVIDED FOR }\end{array}$ & OTHERWISE \\
\hline
\end{tabular}

originally proposed by the authors of Reference (Kryssanov et al., 2005). The framework deals with the observed behavior of a complex system (e.g. social, economic, biological, etc.), and it allows for the evaluation of the internal, "hidden" structure and dynamics of the system, based on estimated parameters of the observed stochastic process (i.e. the system's behavior as registered).

Specifically, to explore the mechanisms of patent generation, the following model characterizing the dynamics and structure of the social network in focus has been used (also see Kryssanov et al., 2006):

$$
P(k)=\sum_{i=1}^{M} c_{i}\left(\frac{b_{i}^{v_{i}}}{\left(k-1+b_{i}\right)^{v_{i}}}-\frac{b_{i}^{v_{i}}}{\left(k+b_{i}\right)^{v_{i}}}\right), k=1,2, \ldots
$$

where parameters $b>0, v>0$, and $P(k)$ is the probability mass function of the occurrence (count) of the network's observed state change.

It should be emphasized that the well-studied form of the power law $P(k)=v b^{v} / k^{v+1}$ (Pareto 1 distribution) is a particular case of the more general distribution (1) when the investigated system is homogeneous (i.e. when $M=1$ ). In the latter case, an "equivalent" of the Zipf's law for the rank statistics can be written as $f_{r}=b l^{-1+1 / v} r^{-1 / v}-b l^{-1}$, where $f_{r}$ is the relative occurrence frequency of the $r$-th popular unit. While the rank-frequency form is, perhaps, most often used in the studies of patent and article authorship- networks, we will employ the general form (1) to explore the dynamics and structure of inventorship networks in Japanese manufacturing companies. The observed property (as represented by the stochastic variable $k$ ) is, in this case, the number of patents filed by an individual. It will thus be assumed that filing (registering) a patent indicates a change in the internal dynamics of the corresponding social system.

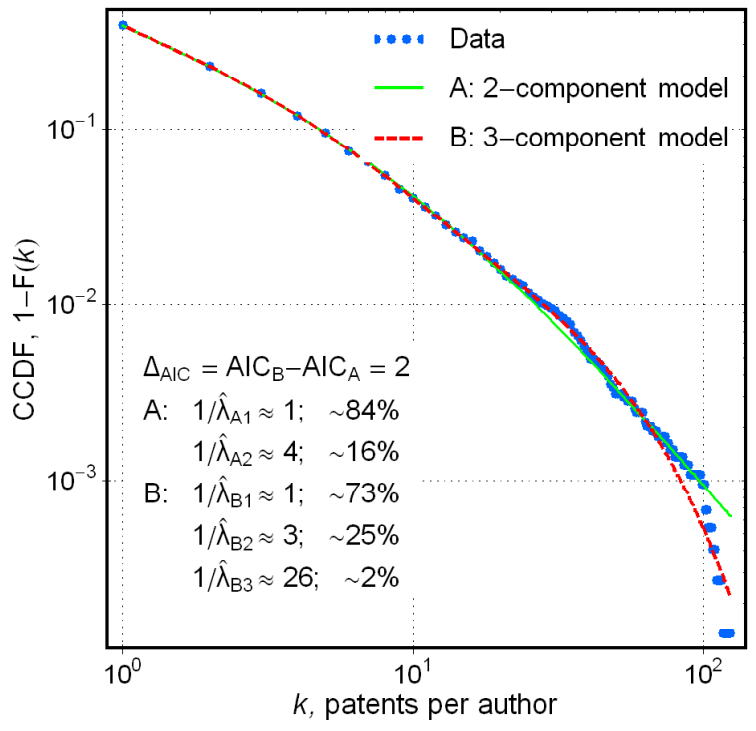

Figure 2: Results of the modeling of the Japanese companies' patent network. $1 / \lambda$ is an estimate of the average number of patents per author; $E(\lambda)=v / b$.

\section{INVENTORSHIP NETWORKS}

Data used in the following analysis is a sample representing the number of patents applications filed for 7,396 inventors (totally 9,349 applications) using specific IPC (International Patent Classification at WIPO - World Intellectual Property Organization) categories about micromachining-techniques (Table 1) in Japan during 1988-2003. In this section, an analysis of the specific sub-set (the IPC categories) of the data is done, and its results are used to detect the structure of the patent creation process.

Figure 2 shows the results of modeling the patent authorship with 2-component and 3-component models from the previous section (i.e. for $M=2$ and 3 , respectively). A traditional model would suggest only 1 component represented by a single straight 
line in the double-logarithmic chart, which is obviously not the case for this data. In the analysis, the 2-component model appears to be a better choice, based on the parsimony principle ("the best is the simplest model"), since the AIC difference Akaike's Information Criterion assesses the relative Kullback-Leibler distance between the fitted model and the unknown true mechanism, which actually generated the observed data (Akaike, 1983) - is not too large (models may be considered equivalent or at least close when $\Delta \mathrm{AIC} \leq 2$ (Sakamoto et al., 1986)). Both models, however, suggest that there are two subsystems, "static" ( 20\%) and "dynamic" $(\sim 80 \%)$, in the social network investigated. The static system appears to be due to basic study activities in the R\&D (or "pure" research) section of a company, while the dynamic system due to innovation activities in the mass production process (incremental improvements, etc.).

It is thus proposed that the static system is based on (or is made up of) "basic" or "pure" research. This would be research without a very specific (focused) goal. The dynamic system, on the other hand, could be based on the Japanese idea of incremental improvements. This is research (in a very specific area and, usually, with a very specific goal) to improve an already manufactured product or product design. Figure 3 provides a conceptual image of the two systems to create patents.

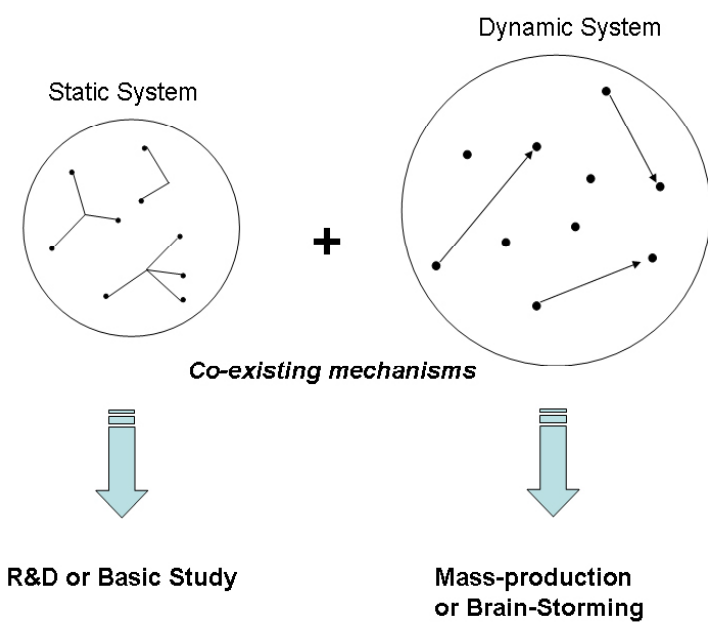

Figure 3: The concept of the patent creation.

\section{PATENT CREATION PROCESSES}

Almost all patents discussed above were created by collaboration of inventors. Regarding the patent categories used in this study, Japanese companies have competitive power in the field of micromachining technique, but do not have it in the IT and the biotechnology areas. In addition, as it follows from the previous analysis, almost all of the patents are created in the dynamic system. In other words, it appears plausible that, in Japanese firms, R\&D departments ("pure research") do not play a major role in the creation of patents.

The previous studies about effective team work suggested that the decisions of team members are important for the success of a project (Bixby, 1987), and referred to factors needed for creative teams, but did not mention the team dynamics.

Japanese manufactures are involved in training processes for innovation, especially focusing on the importance of "Kaizen" (Imai, 1987; Lillrank and Kano, 1990). It is perhaps this culture that caused the observed dynamics in the inventorship networks.

Possible reasons for why the contribution of the innovative activities in the patent creation process is more significant are as follows. If every patent application is valuable, the product development processes prevails over the basic study activities. If, however, the product development has the same impact (priority, etc.) as the basic study activities, then one patent in basic studies is more "powerful" (in terms of the patent authorship, as revealed through the social connections and count of filed patents) than one in product development. Otherwise, the product development processes may naturally result in more patents than the basic study activities.

It has been found through interviews that the presented study findings confirm the general intuition of the respective companies' managers about the structure and the dynamics of the inventive activities.

\section{CONCLUDING REMARKS}

The analysis in the previous section has shown that there are two possible mechanisms of patent creation in Japanese manufacturing companies. The less (observationally) influential mechanism tends to be focused on genuinely new products and new ideas. Traditionally the later has a higher risk (e.g. due to low return on investment), as large jumps in 
technology may not be financially justifiable. In contrast, the more influential mechanism is associated with activities focused on current products and ideas with the goal of enhancing or improving on them. This type of patent creation activities obviously has a better financial justification, as there is more knowledge about the current product and its profitability. Hence, the cost/reward ratio for the incremental patent research makes it easier to justify.

Currently, the process to create patents is often highly inefficient and very costly in Japan; the emphasis on process innovation should be shifted to product innovation in Japanese firms since, in fact, R\&D budgets have been recently increasing without producing economic results (OECD, 2001). If 'process' innovation is driven by the dynamic mechanism, the companies need to change the management system to reduce dynamics in the inventor networks.

In a future study, we will focus on the details of inventorship networks, particularly on the inventors and their (apparent) areas of expertise. This more detailed analysis might suggest ways for a company to increase its synergy between inventors to more quickly develop patents.

Japanese working culture is changing dramatically, and recently it is not enough to focus solely on the organization of a company to grasp its potential. The importance of individual inventors and their connectivity should further be analyzed because they are the source of the patents that largely determine technological strategies.

There are also plans to conduct a similar analysis of other countries' patent data (e.g. the US and the EU) to determine if the patent creation mechanisms within a company environment differ from country to country.

\section{REFERENCES}

Akaike, H., 1983. Information measures and model selection. International Statistical Institute, 44, 277291.

Bhattacharya, S., and Meyer, M., 2003. Large firms and the science-technology interface - Patents, patent citations, and scientific output of multinational corporations in thin films. Scientometrics, 58, 265-279.

Bixby, K., 1987. Superteams, Fontana, London.

Burgelman, R.A., Christensen, C.M., and Wheelwright SC., 2003. Wheelwright, Strategic Management of Technology and Innovation, 4th edition. McGrawHill/Irwin.
Chen, C.M., and Hicks, D., 2004. Tracing knowledge diffusion. Scientometrics, 59, 199-211.

Huang, M.H., Chiang, L.Y., and Chen, D.Z., 2003. Constructing a patent citation map using bibliographic coupling: A study of Taiwan's high-tech companies. Scientometrics, 58, 489-506.

Imai, K., 1987. Kaizen, Random House, New York.

Jaffe, A.B., and Trajtenberg, M., 1996. Flows of knowledge from universities and federal laboratories: Modeling the flow of patent citations over time and across institutional and geographic boundaries. Proceedings of the National Academy of Sciences of the United States of America, 93, 12671-12677.

Kryssanov, V. V., Rinaldo, F.J., Kuleshov, E.L., Ogawa, H., 2006. Modeling the dynamics of social networks. This volume.

Kryssanov, V.V., Kakusho, K., Kuleshov, E.L., Minoh, M., 2005. Modeling hypermedia-based communication. Information Sciences, 174, 37-53.

Lillrank, P., Kano, N.j, 1990. Continuous Improvement: Quality control circles in Japanese industry, University of Michigan Press, Ann Arbor.

Liu, X., Bollen, J., Nelson, M.L., Van de Sompel, H., 2005. Co-Authorship Networks in the Digital Library Research Community. Information Processing and Management, 41, 1462-1480.

Meyer ,M.S., 2001. Patent citation analysis in a novel field of technology: An exploration of nano-science and nano-technology. Scientometrics, 51, 163-183.

Mitzenmacher, M., 2003. A Brief History of Generative Models for Power Law and Lognormal Distributions. Internet Mathematics, 1, 226-251.

Mogee, M.E., and Kolar, R.G., 1999. Patent co-citation analysis of Eli Lilly \& Co. patents. Expert Opinion on Therapeutic Patents, 9, 291-305.

Newman, M.E.J., 2005. Power laws, Pareto distributions and Zipf's law. Contemporary Physics, 46, 323-351.

OECD., 2001. Science, Technology and Industry Outlook, OECD Publishing.

Probert, D., and Shehabuddeen, N., 1999. Technology road mapping: the issues of managing technology change. International Journal of Technology Management, 17, 646-661.

Rivette, K.G. and Kline, D. 2000. Rembrandts in the Attic: Unlocking the Hidden Value of Patents, HBS Press, Boston.

Sakamoto, Y., Ishiguro, M., and Kitagawa, G., 1986. Akaike information criterion statistics, KTK Scientific. Tokyo.

Singh, J., 2005. Collaborative networks as determinants of knowledge diffusion patterns. Management Science, 51, 756-770.

Tijssen, R.J.W., 2001. Global and domestic utilization of industrial relevant science: patent citation analysis of science-technology interactions and knowledge flows. Research Policy, 30, 35-54. 
Verbeek, A., Debackere, K., Luwel, M., Andries, P., Zimmermann, E., and Deleus, F., 2002. Linking science to technology: Using bibliographic references in patents to build linkage schemes. Scientometrics, 54, 399-420.

Verspagen, B., 2000. The role of large multinationals in the Dutch technology infrastructure. A patent citation analysis. Scientometrics, 47, 427-448. 